\title{
Simultaneous Determination of Chloride and Potassium in Carbohydrate Electrolyte Beverages Using an Array of Ion-Selective Electrodes Controlled by a Microcomputer
}

\author{
Julio Cesar B. Fernandes ${ }^{a}$, Graciliano de Oliveira Neto ${ }^{b}$, \\ Jarbas José R. Rohwedder and Lauro T. Kubota ${ }^{a *}$ \\ anstituto de Química, Universidade Estadual de Campinas, CP 6154, 13083-970, Campinas - SP, Brazil \\ ${ }^{\mathrm{b}}$ Centro de Ciências Biológicas e da Saúde, Universidade São Francisco, Bragança Paulista - SP, Brazil
}

Este trabalho descreve a elaboração de um sistema potenciométrico controlado por microcomputador para uso com um conjunto de eletrodos íon-seletivo. O sistema empregou uma placa de interface modeloACL-8111 da ADLink Technology, para controlar a seleção dos eletrodos íon-seletivo, através de uma chave analógica (ADG201), com simultânea aquisição de dados. Um programa escrito na linguagem VISUAL BASIC 4.0 foi empregado para controle e aquisição de dado. Este sistema foi avaliado na determinação simultânea de cloreto e potássio em amostras de bebidas energéticas. Os resultados obtidos na análise destes íons foram concordantes com aqueles dos métodos de referência levando em consideração o erro estimado nas determinações.

\begin{abstract}
This work describes the building of a potentiometric system composed of an array of ion-selective electrodes and controlled by microcomputer. The system employed an acquisition card model ACL8111 from ADLink Technology for the selection control of the ion-selective electrodes through an analogic switch (ADG201) with simultaneous data acquisition. Software implemented on the VISUAL BASIC 4.0 language was employed for electrode control and data acquisition. This system was evaluated in the simultaneous determination of chloride and potassium in samples of carbohydrateelectrolyte beverages. The results obtained for these determinations were in agreement with those obtained by the reference method taking into account the estimated error in the determinations.
\end{abstract}

Keywords: array of ion-selective electrodes, beverages analysis, computational system

\section{Introduction}

Analyses using ion-selective electrodes (ISE) reached its golden age in the 1970's. Potentiometric methods have been little studied in recent years, but today ISE is a ripe technique with a century of detailed studies. In the last years, the potentiometric technique has received particular attention in many analytical applications that requires the simultaneous determinations of ions in samples containing several species ${ }^{1-3}$. The capacity of the ion selective electrodes to analyze ions, even in the presence of interferents makes them very attractive for use in arrays. ISE arrays are widely used for blood electrolyte analysis, where typical determinations of sodium, calcium, potassium, $\mathrm{pH}$ and chloride are necessary. The majority of these arrays is usually associated with dynamic techniques such as flow injection (FIA $)^{4,5}$, sequential injection (SIA $)^{6}$, batch injection analysis (BIA) ${ }^{7}$ or built into flow-cell analyzers. The use of arrays is not very common in steady-state applications.
However, the manufacture of these arrays is relatively complex, involving a combination of techniques such as screen printing, spin coating, accurate drop-on-demand liquid handling, injection molding, or accessories such as solenoid valves for sensor commutation in flow and ideally clean room conditions ${ }^{8}$. These facilities and technologies are rarely found in analytical laboratories industrial, thus simpler solutions would be of interest.

This work reports the construction of a simple system and software elaborated to control the commutation of the potentiometric sensors and data acquisition by the microcomputer. The system was tested for the simultaneous determination of chloride and potassium in carbohydrate-electrolyte beverages, which are commonly used by athletes as a source of replacement of electrolytes lost during physical activity. The consumption of these beverages has increased in the last decade, not only by athletes, but also by children and adolescents ${ }^{9}$. Their basic composition is of sugars and salts ${ }^{10-12}$, which the salt combination replaces the electrolytes that are eliminated 
through sweat, namely, chloride, potassium, sodium, magnesium and calcium ${ }^{13}$. The concentration of these electrolytes in the beverage must supply an osmotic pressure similar to that observed in blood ${ }^{13}$, thus it is very important to check the concentration of electrolytes such as chloride and potassium in carbohydrate-electrolyte beverages.

\section{Experimental}

\section{Reagents}

All chemicals were analytical-grade. Potassium chloride supplied by Merck was used as standard. Tris(hydroxymethyl)aminomethane (TRIS- $\mathrm{SO}_{4}$ ) supplied by Sigma was employed as buffer to adjust the $\mathrm{pH}$. Two samples of carbohydrate-electrolyte beverages were acquired in a local supermarket.

The standard solutions of potassium chloride were prepared with a $0.1 \mathrm{~mol} \mathrm{~L}^{-1}$ buffer at $\mathrm{pH} 7.0$, in the range between $10^{-4}$ and $10^{-1} \mathrm{~mol} \mathrm{~L}^{-1}$. These solutions were used for simultaneous calibration of the chloride and potassium ion-selective electrodes. The analyzed beverages were prepared in a similar manner by the dilution (10 times) of the concentrated solution in the buffer. The chloride electrode was acquired from Corning, model 476126, while the potassium electrode was prepared according to the protocol described by Band and Kratochvil ${ }^{14}$. The membrane composition was 0.73 wt.\% valinomycin (Sigma), 66.86 wt.\% bis-2-etyl hexyl adipate (Fluka), $32.39 \mathrm{wt}$ \% polyvinyl chloride (Aldrich) and 0.02 wt.\% potassium tetrafluorborate (Aldrich). The mixture was dropped on the surface of a graphite/epoxy electrode. Before use, both electrodes were conditioned in a $0.1 \mathrm{~mol} \mathrm{~L}^{-1}$ potassium chloride aqueous solution, for one day. When not in use the potassium electrode was stored dry to avoid the leaching out of the sensing material from the membrane.

\section{Apparatus}

Figure 1 shows a schematic diagram of the system used for electrode commutation, solution agitation velocity control and data acquisition. The system is based on ACL8111 card from ADLink Technology associated to $\mathrm{pH} / \mathrm{Ion}$ Analyzer from Corning model 350 and personal computer with a $133 \mathrm{MHz}$ AMD 586/P75S processor and a memory size of $12 \mathrm{Mb}$. The parallel interface, ACL-8111, has the following features:

-1 A/D converter of 12-bit resolution;

-16 input and output digital channels.

Seven digital output channels of least significant bit (LSB) were used to control a programmable crystal oscillator
(301-864), which provides 57 different output frequencies in the range from $0.005 \mathrm{~Hz}$ to $1 \mathrm{MHz}$. The motor speed of agitation, a DC-micromotor, type 2233T4.5 S from Minimotor SA, is obtained through pulse modulation ${ }^{15}$. Basically, the time period that the motor remains on/off is responsible for the velocity, this being a function of the frequency. The motor-system allowed an agitation velocity between 0 and $800 \mathrm{rpm}$ under liquid charge (water), which was calibrated with a tachometer from Minipa, model MDT-2244. Four digital output channels of most significant bit (MSB) were employed to control an analog switch (ADG201), which was used for the electrode commutation in a similar manner to those reported elsewhere ${ }^{16}$. In the ON state (voltage zero), this integrated circuit conducts current in either direction, maintaining the resistance nearly constant over its signal handling range. In the OFF state, it blocks the voltages making the switch $\mathrm{V}(+)$ and $\mathrm{V}(-)$ equal. Thus, the logic level changing in the switch, which is connected to the sensor, can enable the desirable electrode. When the logic level is low in pin 01 (vide Figure 1), the others pins (08, 09 and 16) shall be high $\left(0111=2^{0} \times 0+2^{1} \times 1+2^{2} \times 1+2^{3} \times 1=14\right)$, thus, the electrode connected to the first switch is available to read. By the commutation of the logic levels for $(1011=13)$, $(1101=11)$ and $(1110=07)$ the electrodes enabled shall be the second, third and fourth, respectively. For data acquisition the analog to digital 12 bits converter of the ACL-8111 card was used and connected directly to the recorder output of the $\mathrm{pH} / \mathrm{Ion}$ Analyzer. Software was elaborated to control this system.

The potential measurements were realized simultaneously with two electrodes, chloride and potassium, by using a double-junction $\mathrm{Ag} / \mathrm{AgCl}$ reference electrode (Corning, model 476370) with $1.0 \mathrm{~mol} \mathrm{~L}^{-1} \mathrm{LiNO}_{3}$ as internal filling solution.

The obtained results for chloride and potassium determination in carbohydrate-electrolyte beverages with the system were compared to the reference methods, potentiometric titration with $0.100 \mathrm{~mol} \mathrm{~L}^{-1} \mathrm{AgNO}_{3}$ for chloride and flame photometry for potassium.

\section{Results and Discussion}

\section{Software implementation}

For the data acquisition card, ACL-8111, commutation of the electrodes and the agitation velocity of the solution, software on the oriented language object was implemented in VISUAL BASIC 4.0. The DLL library (inpout32.dll), which allows access to the commands for the I/O data control was obtained from the Internet ${ }^{17}$. This 


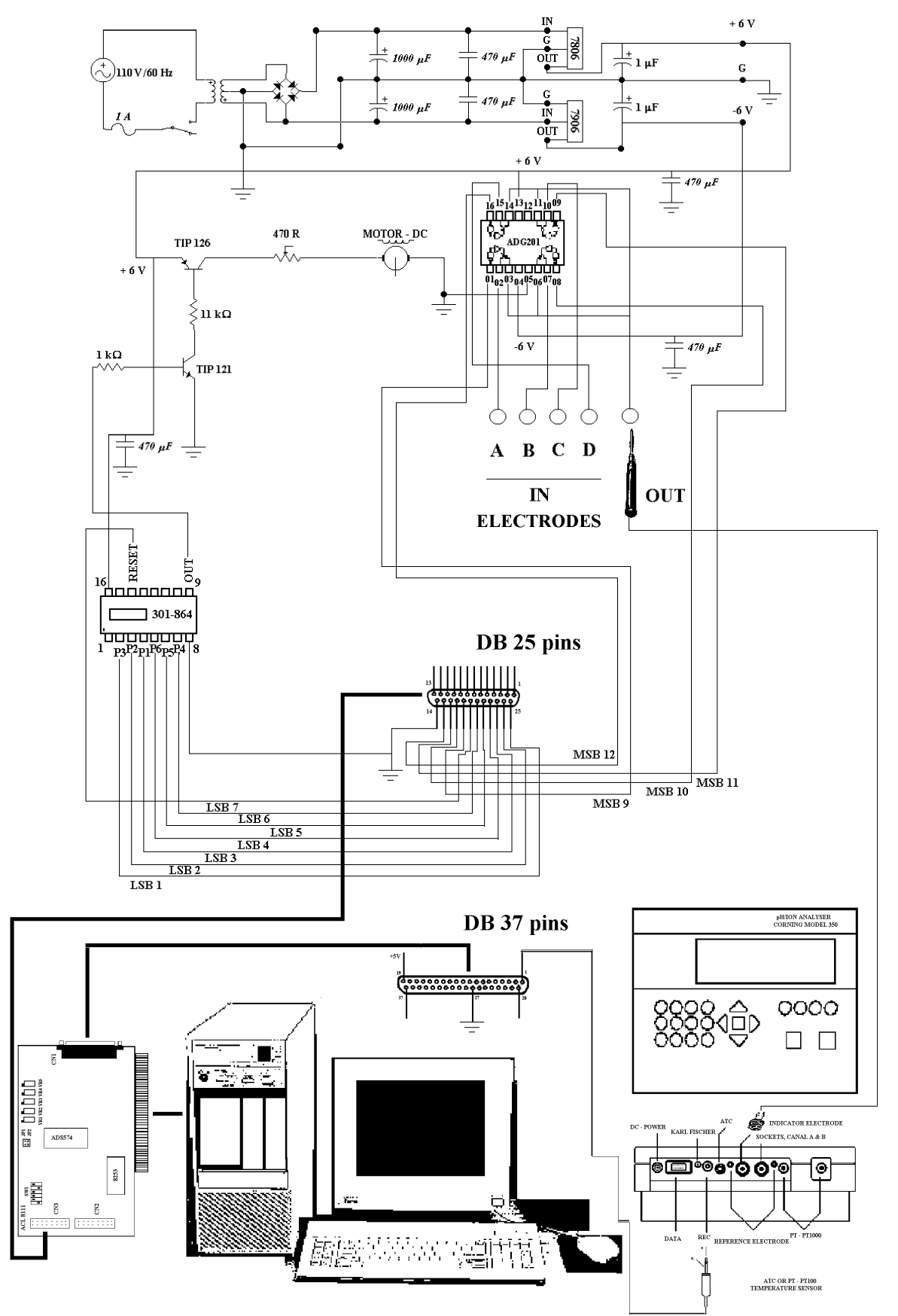

Figure 1. Schematic diagram of the electronic circuit elaborated to the electrode commutation, agitation control and data acquisition.

library was allocated in the directory $\mathrm{C}$ : $\mid$ Windows $\backslash$ System. The structure of the software was elaborated according to the block diagram of Figure 2. Initially, a selection of the electrode numbers that were to be used in the analysis, the acquisition mode and analysis parameters, was made before starting the system. For data acquisition, two modes are possible, manual or automatic. In the manual mode, the system stays continuously acquiring data while in automatic, the use of dynamic techniques where the injected volume through a selection valve or solenoid valve can be also controlled by the software. In this mode, the system automatically stops the acquisition in the sample injection, according to the selected sampling time. Thus, data that have little importance for analysis are not acquired during the sampling period. Other analytical parameters that were selected were the experiment time, acquisition frequency, average number of points and potential range. The acquisition period establishes the time that ACL-8111 card reads the analogical input channel, while the average number of points is the number of points that 
will be used in this period to present the average of the potential, minimizing the noise of the system. It was observed that the minimum time possible for data acquisition with the system is 0.1 second, taking in to account the implemented algorithm and the power of the employed microcomputer. Therefore, this potentiometric system allows the use with FIA or BIA tools, which require a fast response of an ion-selective electrode when the solutions pass over the electrode surface at high flow-rates (FIA) or when a sample volume to high injection-rate are injected on the electrode surface (BIA). Hara et al. ${ }^{18}$, reported a high-speed potentiometric analyzer for use with FIA, which employed solenoid valves as switchover for the solution change reducing the analysis time for one sample to about $1 \mathrm{~s}$. In this work, the proposed system presents a similar performance to those observed by Hara et al. ${ }^{18}$, as well as flexibility and simplicity in its implementation, and a lower cost. The potential range is associated with the plot scale in the output of the display. The injection rate, injector distance, injection volume and flow-rate were implemented for use with BIA or FIA systems and it was not necessary in the steady-state measurements.

Figure 3 shows the graphic interface where the agitation motor, the electrode commutation and data acquisition are controlled, as well as the signal obtained for standards and samples, in the simultaneous determination of chloride and potassium in carbohydrate-electrolyte beverages. The potential measurements of standard solutions were acquired in intervals of $8 \mathrm{~min}$, with $2 \mathrm{~min}$ in stand by waiting to permutation for a new concentration. A similar procedure was employed for the samples. There was no significant difference observed between the potential values acquired by the acquisition card and the ones shown in the display of the $\mathrm{pH} /$ Ion Analyzer. The differences were always less than $3 \mathrm{mV}$.

\section{Analytical performance of the system}

The main parameter that affected the signal in the potentiometric measurements was the solution $\mathrm{pH}$. The samples presented a pH 2.4 (sample \#1) and 3.0 (sample \#2). However, the optimum $\mathrm{pH}$ range for chloride and potassium electrodes are in the range 3-10 and 2-10, respectively. Consequently, a $\mathrm{pH}$ near to neutrality was chosen for making the potentiometric measurements. Thus, all solutions were prepared in $0.1 \mathrm{~mol} \mathrm{~L}^{-1}$ Tris buffer, at $\mathrm{pH}$ 7.0.

The linear regression results obtained with the chloride and potassium electrodes for the calibration range $10^{-4}$ to $10^{-1} \mathrm{~mol} \mathrm{~L}^{-1}$ were, respectively:

$\Delta E=(32 \pm 1)+(56.3 \pm 0.5) p C l^{-}$

with $\mathrm{r}=0.99991$ to $\mathrm{N}=4$ and $\mathrm{SD}=1.22$.

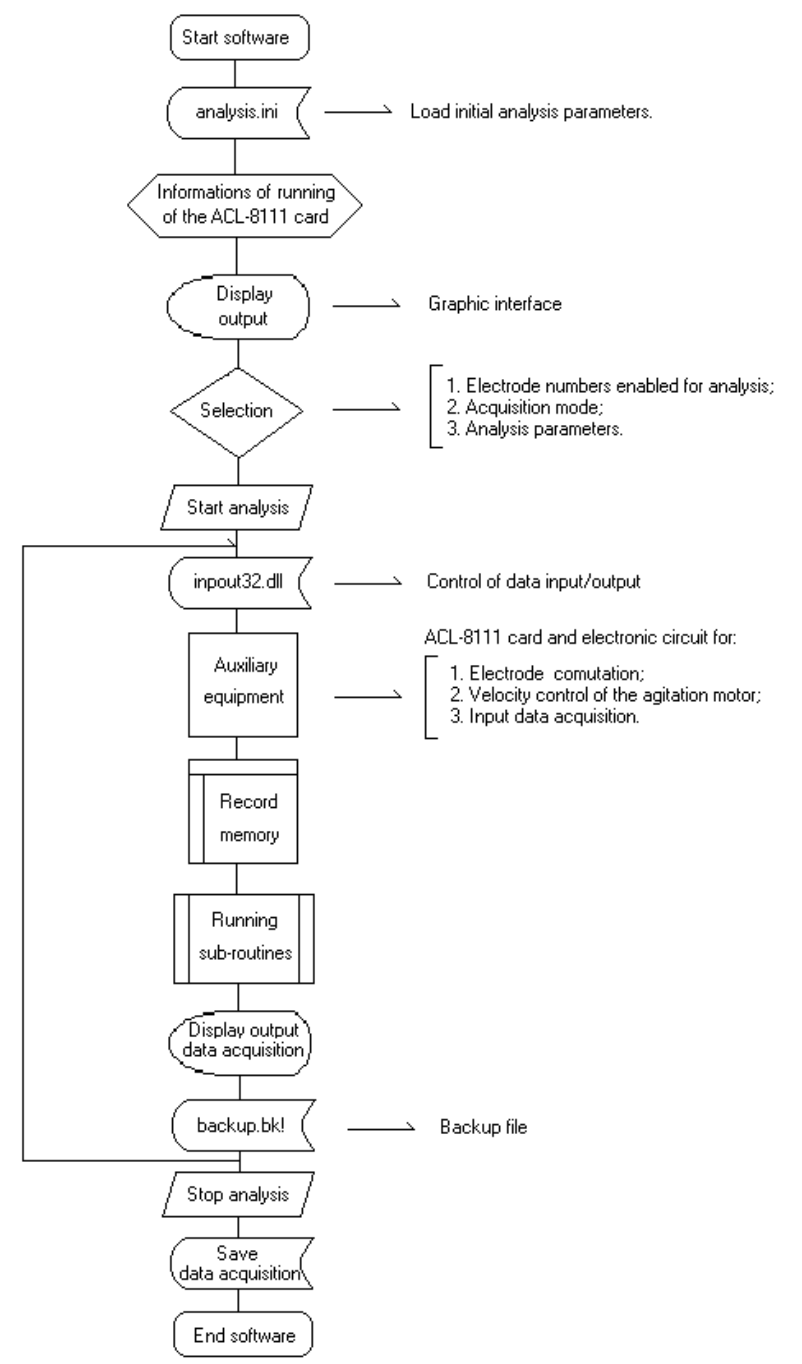

Figure 2. Block diagram of the logical structure implemented in the software for computational control of the ACL-8111 card.

$\Delta E=(118 \pm 2)-(56.1 \pm 0.8) p K^{+}$

with $\mathrm{r}=0.9998$ to $\mathrm{N}=4$ and $\mathrm{SD}=1.79$.

The results for the chloride and potassium determination in carbohydrate-electrolyte beverages are listed in Table 1, as well as the ones obtained by the reference methods. The samples contained several compounds in its formulation, such as sweeteners, vitamins ( $\mathrm{C}$ and $\mathrm{E}$ ), proteins and lipids, but no interference was observed. There was no significant difference between the reference and the proposed method, when taking into account the estimated error in the determinations.

Naturally, the use this computational system with the array of ion-selective electrodes allowed a reduction in the analysis time, by at least half, and by taking into consideration the time required to performe potentiometric measurements individually. It is very important to keep in mind that the computational system elaborated here 


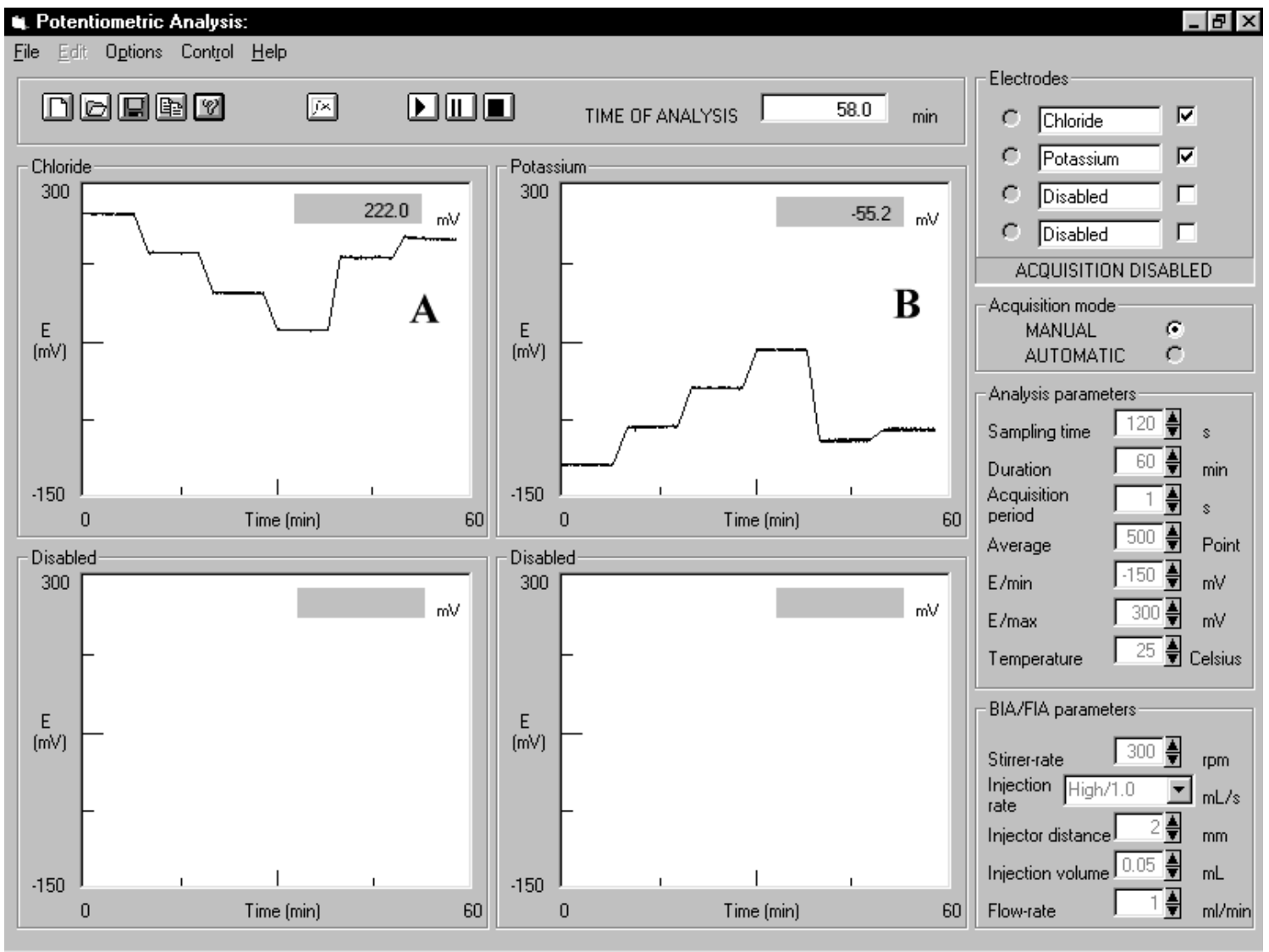

Figure 3. Graphic interface of the software elaborated in VISUAL BASIC for system control, as well as the potentiometric signal obtained to the measurements of standards and samples of chloride (A) and potassium (B) with ion-selective electrodes, respectively. Left to right, standard concentrations $\left(\mathrm{mol} \mathrm{L}^{-1}\right): 10^{-4} ; 10^{-3} ; 10^{-2} ; 10^{-1}$; samples (10 times diluted): \#1 and \#2. Agitation velocity: $300 \mathrm{rpm}$.

allows the simultaneous use of four electrodes, however the array allows for expansion of the number of electrodes for analysis to eight by the addition of one more analog switch (ADG201), as the acquisition card has four digital output channels of most significant bit (MSB) that are available. Moreover, it is possible to use this computational system with the implemented software, in association with the dynamic techniques, such as FIA and BIA.

\section{Conclusion}

The proposed system allowed the implementation and maintenance, moreover it requires simple and low cost electronics components. The use of an ion-selective electrode array showed that potentiometry is useful for this purpose, as it increases the versatility of this technique.

The application of this technique for the determination of chloride and potassium in beverages is very important, due to the high levels of fruit juice production in the world where these juices contain considerable amounts of these ions.

Thus, the development of potentiometric instrumentation allowing improved analytical procedures is an important area of interest that will be investigated in the near future.

In this work, all measurements were performed in a steady state, however the proposed system may be associated to dynamic techniques without problems.

\section{Acknowledgements}

The authors acknowledge FAPESP (Fundação de Amparo à Pesquisa do Estado de São Paulo) for the financial support and Prof. Heloise O. Pastore for revision of the english manuscript. JCBF is indebted to FAPESP for a fellowship.

\section{References}

1. Lemke, U.; Camman, K.; Kötter, C.; Sundermeier, C.; Knoll, M. Sens. Actuators 1992, B7, 488.

2. Forster, R. J.; Regan, F.; Diamond, D. Anal. Chem. 1991, 63, 876.

3. Dimitrakopoulos, T.; Alexander, P. W.; Hibbert, D. B. Electroanalysis 1996, 8, 438. 
4. Forster, R. J.; Diamond, D. Anal. Chem. 1992, 64, 1721.

5. Diamond, D.; Forster, R. J. Anal. Chim. Acta 1993, 276,75 .

6. Luca, G. C.; Reis, B. F.; Zagatto, E.A. G.; Montenegro, M. C. B. S. M.; Araújo, A. N.; Lima, J. L. F. C. Anal. Chim. Acta 1998, 366, 193.

7. Diamond, D.; Lu, J.; Chen, Q.; Wang, J. Anal. Chim. Acta 1993, 281, 629.

8. Lynch, A.; Diamond, D.; Lemoine, P.; McLaughlin, J.; Leader, M. Electroanalysis 1998, 16, 1096.

9. Sichert-Hellert, W.; Kersting, M.; Schoch, G. Int. J. Food Sc. Nutrit. 1999, 50, 65.

10. Maughan, R. J.; Owen, J. H.; Shirreffs, S. M.; Leiper, J. B. European J. Appl. Physiol. Occupat. Physiol. 1994, 69, 209.

11. Helmke, P. A.; Ney, D. M.J. Agric. Food Chem. 1992 , 40, 1547.
12. Geilman, W. G.; Schmidt, D.; Herfurthkennedy, C.; Path, J.; Cullor, J. J. Dairy Sc. 1992, 75, 2364.

13. Lopez, L.; Depenna, E. W.; Bunger, A.; Fuenzalida, R.; Giacchero, C.; Santana, R.Arc. LatinoAmer. Nutric. 1994, 44, 256.

14. Band, D. M.; Kratochvil, J.J. Physiol. (London) 1977, 265, 5P.

15. Wobschall, D. In Circuit Design for Electronic Instrumentation - Analog and Digital devices from Sensor to Display; Second edition; McGraw-Hill Book Company; New York, 1987, p. 367-368.

16. Freire, R. S. Ph.D. Thesis, Universidade Estadual de Campinas - UNICAMP, 1998.

17. http://149.69.43.7/jason/visualb.htm, 1998.

18. Hara, H.; Ishio, N.; Takahashi, K. Anal. Chim. Acta 1993, 281, 45 .

Received: May31, 1999

FAPESP helped in meeting the publication costs of this article. 